\title{
Local deepening of large shallow peat lakes: a measure to improve their ecological status
}

\author{
Willemijntje E. PENNING ${ }^{1,2) *}$, Rob UITTENBOGAARD ${ }^{1)}$, Maarten OUBOTER $^{3)}$ and Ellen VAN DONK ${ }^{2)}$ \\ ${ }^{1)}$ Deltares Delft Hydraulics, p.o. box 177, 2600MH Delft, The Netherlands \\ ${ }^{2)}$ Netherlands Institute of Ecology, NIOO-KNAW-Centre for Limnology, Rijksstraatweg 6, 3631 AC Nieuwersluis, The Netherlands \\ ${ }^{3)}$ Waternet, p.o.box 94370, 1090 GJ Amsterdam, The Netherlands \\ *e-mail corresponding author: ellis.penning@deltares.nl
}

\begin{abstract}
Fine organic suspended sediments (refractory detritus) play an important role in the underwater light attenuation of large shallow lakes with a peat origin and a eutrophication history. Wind driven resuspension of this material, its flocculation in the water column and the settlement of the formed flocs are the main processes governing the dynamics of this material. For restoration of the macrophyte community in such lakes, reduction of this refractory detritus to improve underwater light climate is the key process when eutrophication reduction measures alone are not effective enough. The shallow Lake Loosdrecht (The Netherlands) was used as case study to illustrate the effects of artificially created deepenings on suspended matter concentrations and the consequences for the underwater light climate. Suspended sediment balances were created for the current situation and the situation with deepenings. Field measurements were taken to quantify various processes and results of the calculations from the suspended sediment balances were used to quantify the effects on light climate and potential habitat for macrophytes. These calculations show that creating deepenings (three sections with a total surface area of 120 ha and a depth of $12 \mathrm{~m}$ on a $10 \%$ section of the lake) decreases the concentration of organic detritus by $25 \%$ and decreases attenuation coefficients from $2.5 \mathrm{~m}^{-1}$ to $2.2 \mathrm{~m}^{-1}$. P-load reductions affecting chlorophyll-a levels lead to a change of attenuation coefficients from $2.5 \mathrm{~m}^{-1}$ to $2.0 \mathrm{~m}^{-1}$. The combination of deepenings with P-load reduction measures gives the most optimal result and leads to a predicted attenuation coefficient of $1.6 \mathrm{~m}^{-1}$. These improvements of the underwater light climate are a first step to the recovery of the submerged macrophyte community.
\end{abstract}

Key words: lake restoration, eutrophication, suspended matter, macrophytes, light attenuation, flocculation, Lake Loosdrecht

\section{INTRODUCTION}

The Water Framework Directive (European Union 2000) requires water bodies to be of good ecological and chemical status. In cases where the current status is lower than the predefined 'good status' boundary, measures need to be taken to improve the ecological functioning of the system. Eutrophication is considered the major pressure for most water bodies in Europe (Gulati \& Van Donk 2002; Lyche Solheim et al. 2008) and nutrient reduction from incoming sources is a key measure to improve ecological status. Although nutrient load reduction limits primary production by algae, the measure has little effect on in-lake resuspended matter that is also affecting the underwater light climate. The potential habitat for submerged macrophytes, expressed as a light requirement for germination, can thus be limited through the various types of suspended particles (algae and (in-)organic matter). Measures such as biomanipulation, in which benthivorous and zooplanktivorous fish populations are strongly reduced, have proved to be effective shock treatments for several lakes in which current nutrient load was already reduced, but turbidity remained high (Meijer et al. 1999). However, this measure proves to be susceptible to unpredictable factors and has shown in many cases only to be valid for a limited number of years, often due to misjudgment of nutrient status or connectivity and colonization possibilities of benthivorous fish (Søndergaard et al. 2007). In situations where suspended matter is regulated by erosion and sedimentation under influence of wind driven flow and wave action, the methods to limit these physical processes have to be found in non-biological measures. These measures include those that alter the morphological characteristics of the lakes such as creating local deepenings, local shallow zones or fetch reducing barriers (Gulati et al. 2008).

We will use the shallow Lake Loosdrecht (the Netherlands) as an example to illustrate the effects of deepenings on suspended matter concentrations and the consequences for the underwater light climate. This large, very shallow (mean depth $1.77 \mathrm{~m}$ ), eutrophic peat lake (Fig. 1) currently has a poor ecological status, due to high turbidity caused mainly by organic suspended matter. Table 1 gives an overview of the basic characteristics of the lake. In the 1940's up to $50 \%$ of the lake was covered by a Characean dominated vegetation community (a.o. C. aspera, C. globularis and Nitella flexilis) with a transparency of $c a 2 \mathrm{~m}$ Secchi-depth (Best et al. 1984). In the 1960's and 1970's the lake experienced strong eutrophication due to nutrient input 


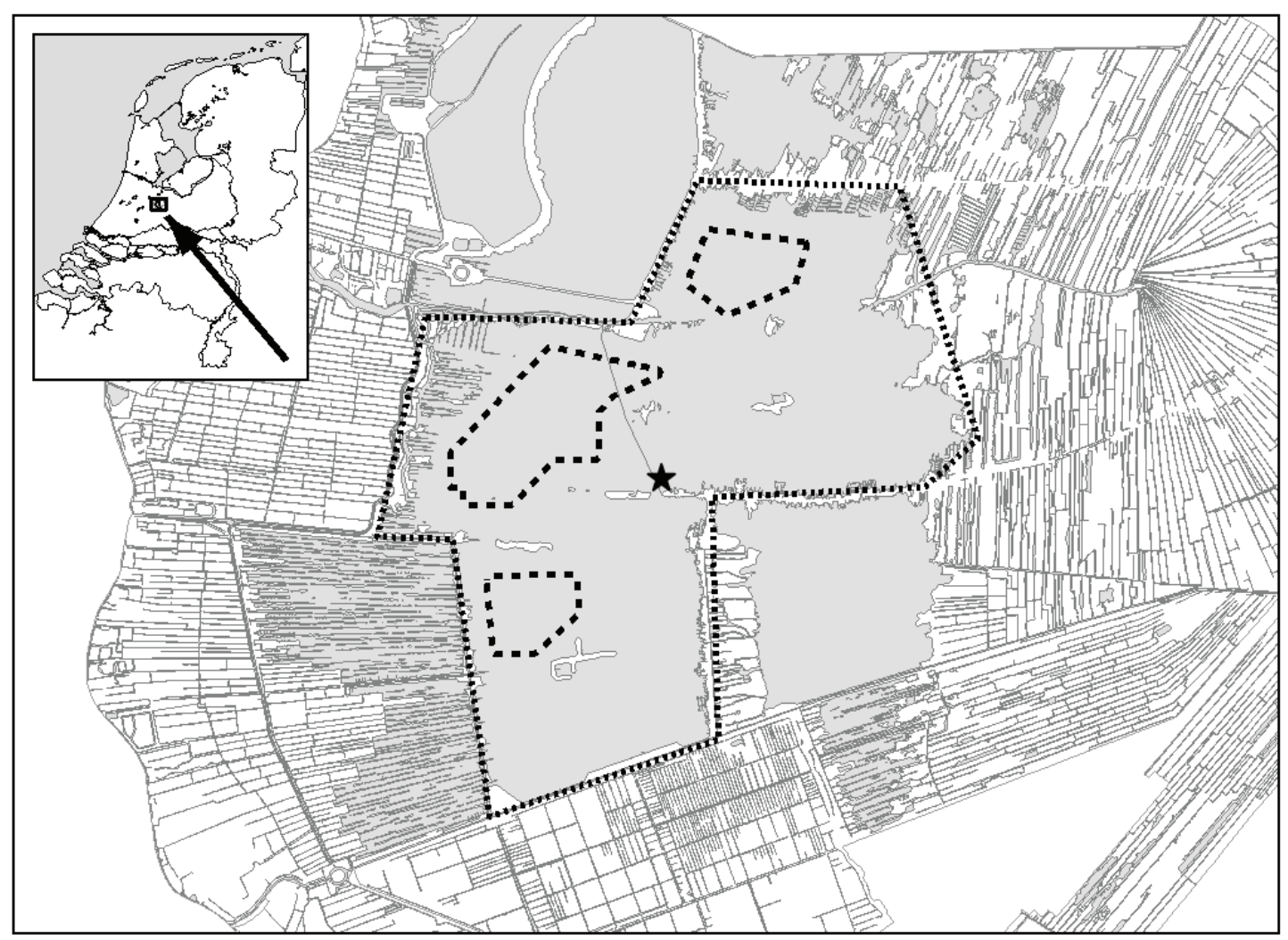

Fig. 1. Location of Lake Loosdrecht in the Netherlands (outlined in small dotted line) and the potential location for 3 deepenings (outlined with large dotted line). Star indicates location of monitoring station.

from external sources, which was reduced in 1984 and thereafter after changes in the management of the incoming waters (Van Liere 1986).

Tab. 1. Overview of characteristics of Loosdrecht lakes.

\begin{tabular}{lc}
\hline Surface area $(\mathrm{ha})$ & 1000 \\
Soil type & peat over sand \\
Av. depth $(\mathrm{m})$ & 1.77 \\
max. fetch $(\mathrm{km})$ & 3.5 \\
av. fetch $(\mathrm{km})$ & 1.4 \\
av. spring Chl-a $\left(\mu \mathrm{g} \mathrm{L}^{-1}\right)$ & 50 \\
av. spring extinction coeff. $(\mathrm{m}-1)$ & 2.5 \\
av. org. carbon $\left(\mathrm{mgC} \mathrm{L}^{-1}\right)$ & 4 \\
total fish density $\left(\mathrm{kg} \mathrm{ha}^{-1}\right)$ & 110 \\
benthivorous fish $\left(\mathrm{kg} \mathrm{ha}^{-1}\right)$ & 50 \\
\hline
\end{tabular}

Figures 2A, B and C give an overview of time series of standard monitoring data from the lake for the period 1980-2005, showing the decrease of chlorophyll- $a$ levels and the steady concentration of suspended matter and Secchi disk transparancies. Macrophytes have not recovered after the measures to decrease nutrient input and algae concentrations, mainly as a result of the high turbidity levels, with Secchi disk readings averaging 0.4 $\mathrm{m}$ over the last decade. The organic matter that has accumulated over the last decades due to the eutrophication problems and measurements of oxygen uptake showed that the greater part of the epipelic matter, called refractory detritus, is being decomposed only very slowly (Gons et al. 1986a, b). Based on C:N measurements of the top layer of the sediment, it appears that dead algal matter and peat that is the main soil type in large areas of the lakes each account for about $50 \%$ of the dissolved oxygen uptake (unpubl. data water board). Wind driven resuspension of the detritus is one of the main causes of the current low levels of transparency (Gons et al. 1986a and figure 3, this paper). This was confirmed by mesocosm studies in the lake where in the wind sheltered mesocosms turbidity decreased not only in the absence of fish, but also in the treatments where fish remained present, although to a lesser amount (Van Donk et al. 1994). For details on the lake's origin, history and eutrophication see Best et al. (1984), Van Liere (1986) and Gulati \& Van Donk (2002).

Currently measures are being assessed for their costeffectiveness to improve the clarity of the lake and restore a macrophyte rich situation (dominated by a Characean community) as before the period of eutrophication in line with the WFD requirements. Besides nutrient load reduction, one of the proposed measures is a local intervention in the morphology of the lake bed. It is hypothesized that creating deeper sections on strategic positions reduces the suspended matter concentrations predominantly through dilution of the amount of particles per $\mathrm{m}^{3}$ (next to a small reduction in the area susceptible to wind-driven erosion of the sediment, thereby resuspending dead organic material into the 
water column) and thereby improves the transparency of the lake. This would lead to an improvement of potential habitat for macrophytes as sufficient amount of light reaches a larger part of the bottom.
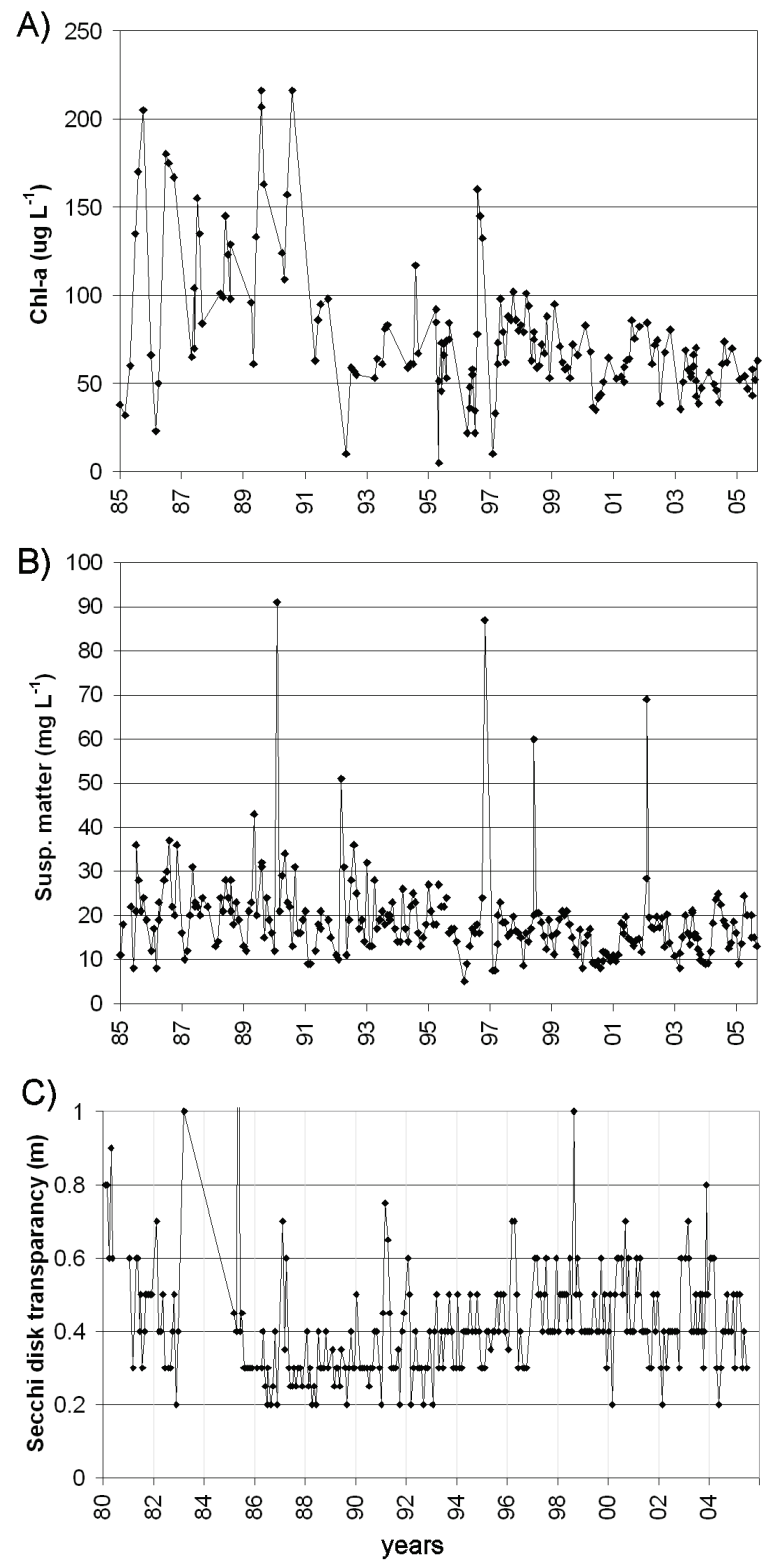

Fig. 2. A) Time series of chlorophyll- $a$ concentrations $\left(\mu g \mathrm{~L}^{-1}\right)$ in Lake Loosdrecht for period 1985-2005; B) time series of suspended matter concentrations $\left(\mathrm{mg} \mathrm{L}^{-1}\right)$ in Lake Loosdrecht for period 1985-2005; C) time series of Secchi disk transparency in Lake Loosdrecht for period 1980-2005.

In this paper we analyze whether deepening (three sections with a total surface area of 120 ha and a depth of $12 \mathrm{~m}$ ) of this shallow lake may help improving its ecological functioning by reduction of the suspended matter concentration, thereby improving the underwater light conditions and creating more potential habitat for macrophytes to colonize.

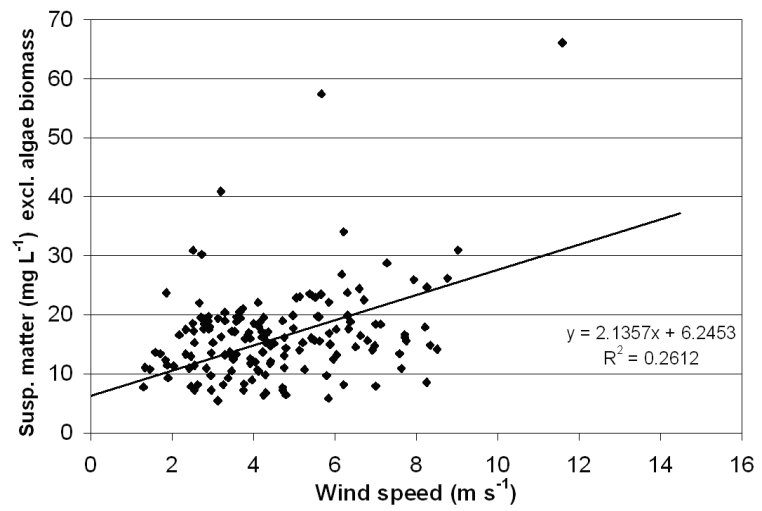

Fig. 3. Relationship between suspended matter concentrations (excluding live algae biomass) and the average wind speed of the day before sampling in Lake Loosdrecht for samples from 1985 to 2005 .

\section{METHODS}

\subsection{Field and laboratory measurements}

To assess several characteristics of the sediment of Lake Loosdrecht four cores of the top $30 \mathrm{~cm}$ of undisturbed sediment were taken to the lab for further analyses. Measurements on the critical shear stresses needed for resuspension of the undisturbed sediment cores were carried out using a rotating vane that stirs the water above the sediment with a known speed as described by Andersen (2001). Critical speeds for erosion of the sediment in the cores was registered by visual inspection. These speeds were translated to critical shear stress values $(\mathrm{Pa})$ following calibration curves of sediments with known Shields parameter characteristics (viz. critical shear stress values of sands of $100 \mu \mathrm{m}$ and $200 \mu \mathrm{m}$ are well known and these were used to relate shear stress to the speed of the vane).

Particle size distributions of the suspended sediments were measured using a Malvern Mastersizer 2000 both before and after centrifuging a water sample for 1 hour at $500 \mathrm{~g}$ to test flocculation speed of the particles and to define the size of the formed flocs. These settings of the centrifuge were defined by a stepwise increase in centrifuging time and analyses in changes in particle size distributions. Samples of particle sizes after centrifuging were taken from the top and bottom of the centrifuge vial as large flocs are grouped at the bottom while a percentage of the small particles that did not floc remain in the top of the vial. The results of the centrifuge testing were transformed into flocculation speeds under normal lake conditions following theory by Van Leussen (1994).

Fall velocity of the formed flocs was determined using a dedicated submerged sedimentation balance onto which flocs were allowed to settle from suspension for 12 hours, following Kowalski (2004). Suspended 
matter samples were further ashed at $450{ }^{\circ} \mathrm{C}$ to define percentage inorganic material within the samples.

\subsection{Annual suspended matter balance}

An annual suspended matter balance of the lake was created, using the information on the field measurements and additional data from the water board 'Amstel, Gooi and Vecht' on lake bathymetry and suspended matter concentrations expressed in $\mathrm{mg} \mathrm{C} \mathrm{L}^{-1}$. In this suspended matter balance we focus on the organic particles smaller than $10 \mu \mathrm{m}$ as they are the main constituent of the suspended matter in Lake Loosdrecht. We assume an equilibrium in the yearly sources and sinks of suspended matter. In this balance the mass flux of floc formation $M_{f l o c}$ of the fine suspended particles depends on the concentration of the suspended particles $\left(C_{\text {suspended }}\right)$ and the time needed for flocculation $\left(T_{\text {floc }}\right)$ :

$$
\dot{M}_{\text {floc }}=\frac{c_{\text {suspended }}}{T_{\text {floc }}} \quad\left[\mathrm{kg} \mathrm{m}^{-3} \mathrm{~s}^{-1}\right]
$$

This mass flux of flocculation is used in the gross sedimentation flux:

$$
V_{L L} \dot{M}_{\text {floc }}=\frac{V_{L L} c_{\text {suspended }}}{T_{\text {floc }}}\left[\mathrm{kg} \mathrm{s}^{-1}\right]
$$

Together with the incoming sources of suspended matter (primary production and decay of peat) and sinks (deepenings and mineralization) this flux is in equilibrium with the production of suspended matter from the fluid fluffy sediment layer that forms the most upper layer of the sediment. As the volume of Lake Loosdrecht (VLL) affects the flocculation process the equation 2.2 can be rewritten as:

$$
V_{L L} \dot{M}_{\text {floc }}=A_{L L}\left(\frac{h_{L L}}{T_{\text {floc }}}\right) c_{\text {suspended }} \quad\left[\mathrm{kgs}^{-1}\right]
$$

showing that sedimentation due to flocculation is a volume-based process, while the net sedimentation velocity is based on a lake surface area. Also equation 3 shows that given the annual production of suspended matter, even in a situation where all sedimented matter is fixed to the bottom (no erosion) a minimal concentration of suspended matter is larger than zero. In this erosion-free situation there is a balance between net production of suspended matter and the flocculation speed.

Enlarging the volume of the lake by creating local deepenings can be written as:

$$
\left(V_{L L}+V_{d}\right) \dot{M}_{f l o c}=\left(V_{L L}+V_{d}\right) \frac{c_{\text {suspended }}}{T_{\text {floc }}}\left[\mathrm{kg} \mathrm{s}^{-1}\right]
$$

It shows that without change in source terms a lower concentration of suspended matter occurs when the deepenings are included. The flocculation time $T_{\text {floc }}$ is inversely related with the concentration due to the decreasing chance of collisions between fine particles.
Therefore the concentration of suspended matter does not decrease linearly with the increase in volume but rather with the square root of this volume. A detailed description of the full suspended matter balance is included in Appendix A.

\subsection{Effects of wind on suspended matter}

The monthly monitoring data on suspended matter was related to time series of wind patterns registered at the standard monitoring location 'Airport Schiphol' of the Royal Dutch Meteorological Institute. Hourly wind data (average speed $\left(\mathrm{m} \mathrm{s}^{-1}\right)$ and direction) was averaged for the day before sampling and suspended matter concentrations were corrected for the amount of algal biomass by converting the monthly monitoring data on chlorophyll- $a$ concentrations to biomass, using 0.035 as a commonly accepted average converting factor (e.g., Strickland 1960; Banse 1977; Harris 1978).

Three dimensional hydrodynamic calculations including the effects of wind patterns on waves and flow dynamics were carried out for a 3 month winter and early spring period to estimate the effects of the deepenings on bottom shear stresses and related erosion-sedimentation patterns in the lake, using the software package Delft3D-flow (Lesser et al. 2004) and Delft3D-waves, which incorporates the dynamic wave model SWAN (Booij et al. 1999). Readily available wind data from airport Schiphol from the winter 19871988 was chosen for the Delft3D-analyses as this winter is known to be a good representative of average winter wind conditions in this area. We assessed the winter condition in the $3 \mathrm{D}$ simulations as wind is generally dominant in that season. Some processes such as temperature influences that might affect biological processes (bio-turbation) and thermal stratification which are expected to occur in summer time are not assessed as we focus in this study on the abiotic processes that govern the suspended matter cycles. The locations of the deepenings in the model were selected based on their distance to the shoreline ( $>100 \mathrm{~m}$ from shoreline) and located an area predominantly subjected to sedimentation. The maximum depth of the deepenings was predefined to be $12 \mathrm{~m}$. Additional calculations were made in which the area available for erosion was stepwise decreased, mimicking the coverage of such an area through colonization of macrophytes.

\subsection{Calculation of attenuation coefficient and potential habitat for macrophytes}

Attenuation of light was calculated for PAR (400$700 \mathrm{~nm}$ ) conform Buiteveld (1995) in which spectral attenuation characteristics are taken into account for all substances contributing to the attenuation of light: algae, organic suspended matter (detritus), humic acids, anorganic suspended matter and water itself. Monthly monitoring data (1982-2006), obtained via standard 


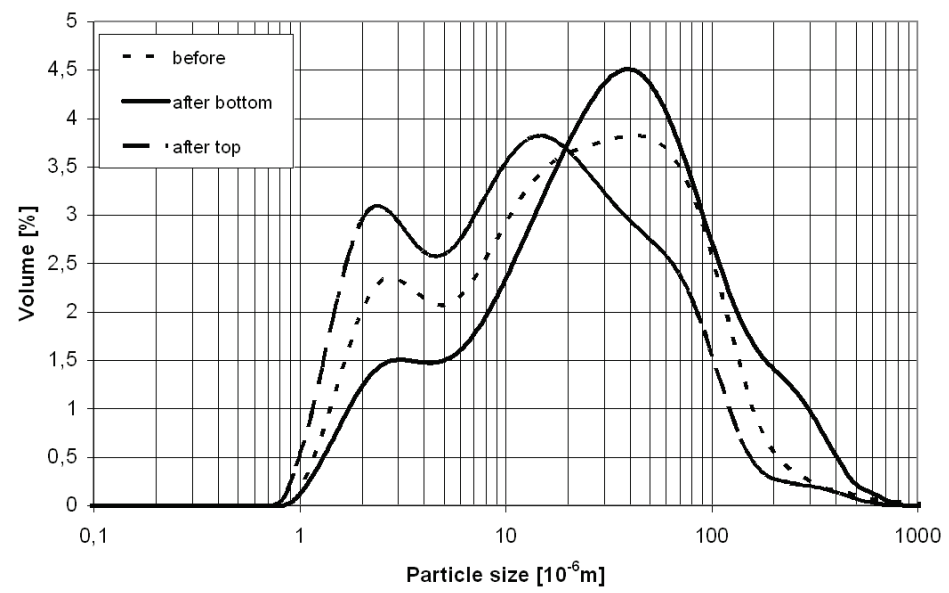

Fig. 4. Change in particle size distribution $(\mu \mathrm{m})$ in a suspended sediment sample from before centrifuging (dotted line) to after centrifuging (semi-solid and solid lines for top and bottom of vial) for 1 hour at $500 \mathrm{~g}$.

protocols ${ }^{1)}$, from the regional water board 'Amstel, Gooi and Vecht' on these substances from a representative monitoring location in the lake (MBP005) was used as a first input to validate the model and define the current situation of the light climate in the lake, expressed as an attenuation coefficient.

After this, calculations were performed linking lake bathymetry to the calculated attenuation coefficients to define the potential area suitable for macrophytes given the requirement that $4 \%$ of the surface light must reach the bed as a minimum for germination opportunities for submerged macrophytes. This requirement is predominantly based on field measurements carried out in various lakes in the Netherlands relating light availability and in-situ multi-species seed bank density to germination chances (unpubl. data M.S. van den Berg \& S. Delauney), focusing on commonly present species, mainly eloedids and charids. Also, various literature sources indicate that germination can occur in similar light availability conditions (e.g., De Winton et al. 2004; Küster et al. 2004; Kalin \& Smith 2007; Istvanovics et al. 2008).

Three subsets of predefined chlorophyll- $a$ concentrations were combined with a decreasing concentration of organic suspended matter (from $5 \mathrm{mg} \mathrm{C} \mathrm{L}{ }^{-1}$ to $1.7 \mathrm{mg}$ $\mathrm{C} \mathrm{L} \mathrm{L}^{-1}$ following the results of the suspended sediment analyses) to define the attenuation coefficients in these combinations of algae and suspended particle concentrations as a sensitivity analysis for the effect of reduced suspended matter (deepenings) vs reduced primary production (P-load reduction). The three different predefined chlorophyll- $a$ concentrations selected were: $50 \mu \mathrm{g}$ $\mathrm{L}^{-1}$, which is representative for the current average winter and spring situation, $40 \mu \mathrm{g} \mathrm{L}^{-1}$ and $30 \mu \mathrm{g} \mathrm{L}^{-1}$ both representing a step in decreasing eutrophication pressure

\footnotetext{
1) Chlorophyll- $a$ via NEN-standard 6520, suspended matter via NENstandard 6499, Attenuation at $380 \mathrm{~nm}$ via photospectrometry using samples filtered over $45 \mu \mathrm{m}$ filter, total attenuation in the field using a $\mathrm{Li}$-Cor underwater sensor $\mathrm{Li}$-192SA.
}

through reduction in P-load to the lake. We have not directly linked P-load reduction to the used algal concentrations, but assume these to be representative for the potential reduction. Neither have we directly assessed the effects of a macrophyte stand on the amount of algae in the stand and thereby positive feedback mechanisms on the light climate in this stand. The used concentrations show the bandwidths within which light attenuation is determined by both organic suspended sediments and chlorophyll- $a$ levels. The potential area available for macrophyte development was then calculated using these attenuation coefficients in combination with the hypsometry of the lake. As very shallow areas $(<0.9 \mathrm{~m})$ do not exist in the lake, wind and wave driven mechanical limitation of macrophyte development (Chambers 1987; Schutten et al. 2004) was not considered of any influence in the lake. This results in curves for each chlorophyll- $a$ concentration in which the potential area available was plotted against the concentration suspended matter.

The graphs of potentially available area for macrophyte development based on suspended matter and chlorophyll- $a$ concentrations were linked to the graphs for the suspended matter concentration in the situations with and without the deepenings in relation to the area no longer susceptible to erosion due to e.g. the presence of macrophytes or capping with sand. With these results we obtain the cross points of the light attenuation lines and the suspended matter reduction lines from the suspended sediment balance. These cross points represent potential equilibria for area covered by macrophytes and a suspended matter concentration, including the attenuation coefficient belonging to this point.

\section{RESULTS}

\subsection{Field and laboratory measurements}

The increase in particle size distribution of the current suspended matter concentration after 1 hour of centrifuging at $500 \mathrm{~g}$ is shown in figure 4. The homogenous distribution of particles in the vial before 
Tab. 2. Suspended matter balance for the current situation and the situation with deepenings, in which fixed input parameters in bold and calculated outputs in italics.

\begin{tabular}{|c|c|c|c|c|}
\hline $\begin{array}{l}\text { Fixed input parameters and } \\
\text { calculated output parameters }\end{array}$ & Current situation & $\begin{array}{l}\text { Current situation } \\
\text { no erosion }\end{array}$ & With deepenings & $\begin{array}{l}\text { With deepenings } \\
\text { no erosion }\end{array}$ \\
\hline Lake depth (m) & 1.77 & 1.77 & 1.77 & 1.77 \\
\hline Lake volume $\left(\mathrm{Mm}^{3}\right)$ & 17.7 & 17.7 & 17.7 & 17.7 \\
\hline Lake surface $\left(\mathrm{Mm}^{2}\right)$ & 10 & 10 & 8.8 & 8.8 \\
\hline Deepening depth (m from current bed) & $\mathbf{0}$ & $\mathbf{0}$ & 12 & 12 \\
\hline Deepening surface $\left(\mathrm{Mm}^{2}\right)$ & $\mathbf{0}$ & $\mathbf{0}$ & 1.2 & 1.2 \\
\hline Deepening volume ( $\mathrm{Mm}^{3}$ additional to lake volume) & $\mathbf{0}$ & $\mathbf{0}$ & 14.4 & 14.4 \\
\hline Floc size $(\mu \mathrm{m})$ & 200 & 200 & 200 & 200 \\
\hline Floc fall velocity $\left(\mathrm{mm} \mathrm{s}^{-1}\right)$ & 1 & 1 & 1 & 1 \\
\hline Mineralisation time (days) & 1000 & 1000 & 1000 & 1000 \\
\hline Suspended matter size $(\mu \mathrm{m})$ & $1-10$ & $1-10$ & $1-10$ & $1-10$ \\
\hline Suspended matter concentration $\left(\mathrm{mgC} \mathrm{L}^{-1}\right)$ & 4 & 1.7 & 3.0 & 1.3 \\
\hline Flocculation time (days) & 20 & 47 & 27 & 62 \\
\hline \multicolumn{5}{|l|}{ Fixed input fluxes } \\
\hline Production Algae (ton $\mathrm{C}^{-1}$ ) & 120 & 120 & 120 & 120 \\
\hline Peat decay (ton $\mathrm{C}^{-1}$ ) & 180 & 180 & 180 & 180 \\
\hline Water input from external sources $\left(\mathrm{Mm}^{3} \mathrm{y}^{-1}\right)$ & 28 & 28 & 28 & 28 \\
\hline \multicolumn{5}{|l|}{ Calculated output fluxes } \\
\hline Mineralisation (ton $\mathrm{C}^{-1}$ ) & -26 & -14 & -35 & -15 \\
\hline Exchange with external sources (ton $\mathrm{C}^{-1}$ ) & -113 & -48 & -84 & -37 \\
\hline Sedimentation $\left(\right.$ ton $\mathrm{C}^{-1}$ ) & 1305 & 238 & 1308 & 248 \\
\hline Erosion (ton $\mathrm{C}^{-1}$ ) & 1144 & 0 & 1127 & 0 \\
\hline Deposition (ton $\mathrm{C}^{-1}$ ) & 161 & 238 & 181 & 248 \\
\hline Suspended matter (ton C) & 71 & 30 & 96 & 36 \\
\hline
\end{tabular}

centrifuging shows that a large volume percentage of particles is between 10 to $40 \mu \mathrm{m}$ in size. After centrifuging the sample of the bottom of the vial shows that a large volume of flocs in the size class up to $10 \mu \mathrm{m}$ has disappeared and that there is a further increase in flocs of a larger size. In the top of the vial predominantly small particles have remained and larger particles have disappeared. Flocs larger than $1 \mathrm{~mm}$ formed after centrifuging have a fall velocity of $c a 1 \mathrm{~mm} \mathrm{~s}^{-1}$, which is sufficient for sedimentation to the bottom. In contrast, the original fine particles have a fall velocity of $0.1 \mathrm{~m} \mathrm{~d}^{-1}$, making it highly unlikely they will ever reach the bottom due to turbulence in the lake. In this concentration it takes under normal lake conditions $c a 20$ days for the flocs to form. When total suspended matter concentrations decrease, the time for flocculation will increase.

The epipelic layer starts moving at Vane induced flow speeds of $c a 3 \mathrm{~cm} \mathrm{~s}^{-1}$ (comparable with $c a 0.01 \mathrm{~Pa}$ bottom shear stress) created by orbital motions due to winds from $c a 4 \mathrm{~m} \mathrm{~s}-1$. At $10 \mathrm{~cm} \mathrm{~s}^{-1}$ ( $c a 0.1 \mathrm{~Pa}$ bottom shear stress, winds of $10 \mathrm{~m} \mathrm{~s}^{-1}$ ) this layer is characterized as a fluid fluffy layer of $20-30 \mathrm{~cm}$. In this moving fluid layer flocs are broken down to their original small size $(<10 \mu \mathrm{m})$ due the mechanical friction. These small particles are moved further upwards in the water column due to turbulence.

\subsection{Suspended matter balance}

Table 2 shows the suspended matter balance parameters and fluxes per year for the current situation and the situation with deepenings, both with and without erosion. Based on the results of the field and labo- ratory measurements the input parameters for the current situation are defined, specifically the average suspended matter size $(1-10 \mu \mathrm{m})$, the suspended matter concentration $\left(4 \mathrm{~m} \mathrm{C} \mathrm{L}^{-1}\right)$ and the flocculation time $(20$ days). Using the suspended matter balance these input parameters are recalculated for the situation without erosion, with deepenings and deepenings without erosion. The flocculation time increases with a decreasing the amount of particles in the water column (see Appendix A, A-3) viz. particles do not encounter each other that often in lower concentrations, so flocculation becomes less likely. The fixed input fluxes are based on information of the Water Board on the functioning of the water system (unpublished data Water Board 'Amstel Gooi en Vecht'). The calculated output fluxes it is shown that the erosion and sedimentation fluxes in the current situation are ten-fold higher than the other fluxes. This implies that the recirculation of the material present in the system is the most dominant process in the suspended matter balance. When macrophytes would be present no erosion would occur and the suspended matter concentration and erosion fluxes strongly reduce. The deepenings themselves allow for a decrease in suspended matter concentration of $25 \%$, which supports creating a larger area for potential macrophyte reestablishment (see $\$ 3.3$ and figure 7).

\subsection{Wind and suspended matter}

Ashing of total suspended matter samples showed that $<1 \%$ of the sample consisted of inorganic material. Therefore we neglect this part of suspended matter in the further analyses. In the present situation organic 

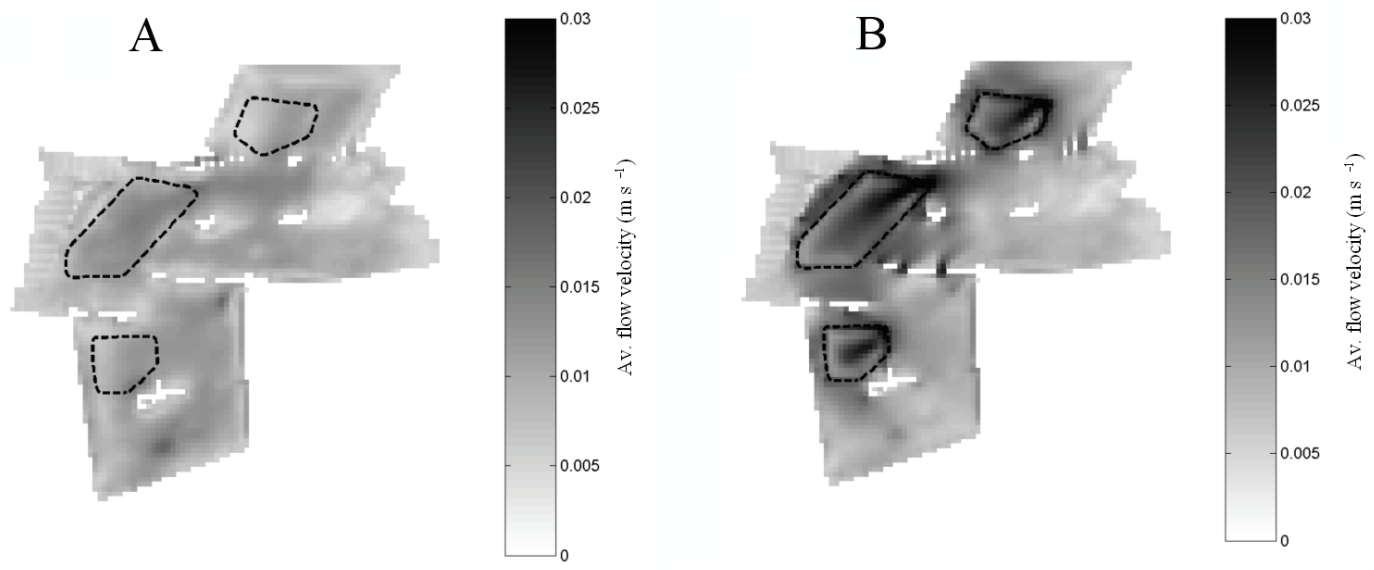

Fig. 5. A) Average flow velocities at the bottom of Lake Loosdrecht from $1^{\text {st }}$ December ' 87 to $1^{\text {st }}$ of February ' 88 for the current situation. B) Average flow velocities at the bottom of Lake Loosdrecht from $1^{\text {st }}$ December ' 87 to $1^{\text {st }}$ of February ' 88 for the situation with deepenings. In both figures the contours of the deepenings are included for reference. Flows in $\mathrm{m} \mathrm{s}^{-1}$.

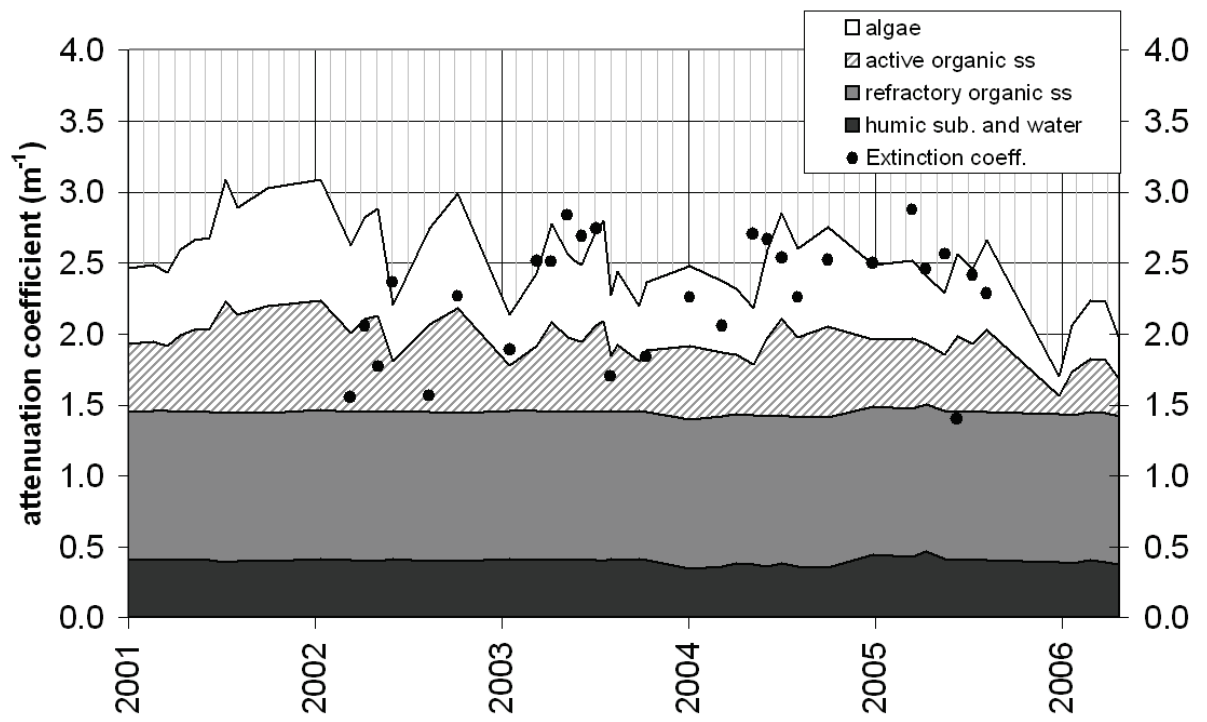

Fig. 6. Calculated and measured attenuation coefficients in Lake Loosdrecht for the period 2001 to 2006 . Indicated are the contributions of each group of substances to the overall attenuation. Dots represent measured attenuation coefficients.

suspended matter (excluding algal biomass) is positively related to an increase in average wind speed, regardless of direction and season, on the day before sample taking (figure $3, R^{2}=0.26$ ). Three-dimensional hydrodynamic calculations show that in the area around the deepenings wind driven currents cause additional erosion of the sediment, due to the change in equilibrium of wind force with the hydrostatic pressure in deep and shallow parts of the lake: in deeper parts a smaller water level displacement is needed than in shallow parts to create flow, resulting in a return flow through the deeper sections (so this is only valid when the deepenings are not comprising the full lake area). This effect of deepenings are shown in figure $5 \mathrm{~A}$ and $5 \mathrm{~B}$ for the average winter flow patterns in the lake using meteorological data from winter '87-'88. So, in the areas of the deepenings chances of erosion occurring are present, despite the increased depth and the lack of direct wave action on the bed.

\subsection{Light climate and potential area for macrophytes}

The calibration of the calculated attenuation coefficients in comparison with measured attenuation coefficients throughout the years 2002 to 2006 is shown in figure 6 . The average variation between measured and predicted value is $0.5 \mathrm{~m}^{-1}(\mathrm{n}=29)$, which is partly caused by a mismatch in timing taking samples for attenuation coefficient and chlorophyll- $a$ concentrations.

The results of the combined calculations of the effect of deepenings and erosion on the current suspended matter concentration and the effect of combined chlorophyll- $a$ and suspended matter on light availability 


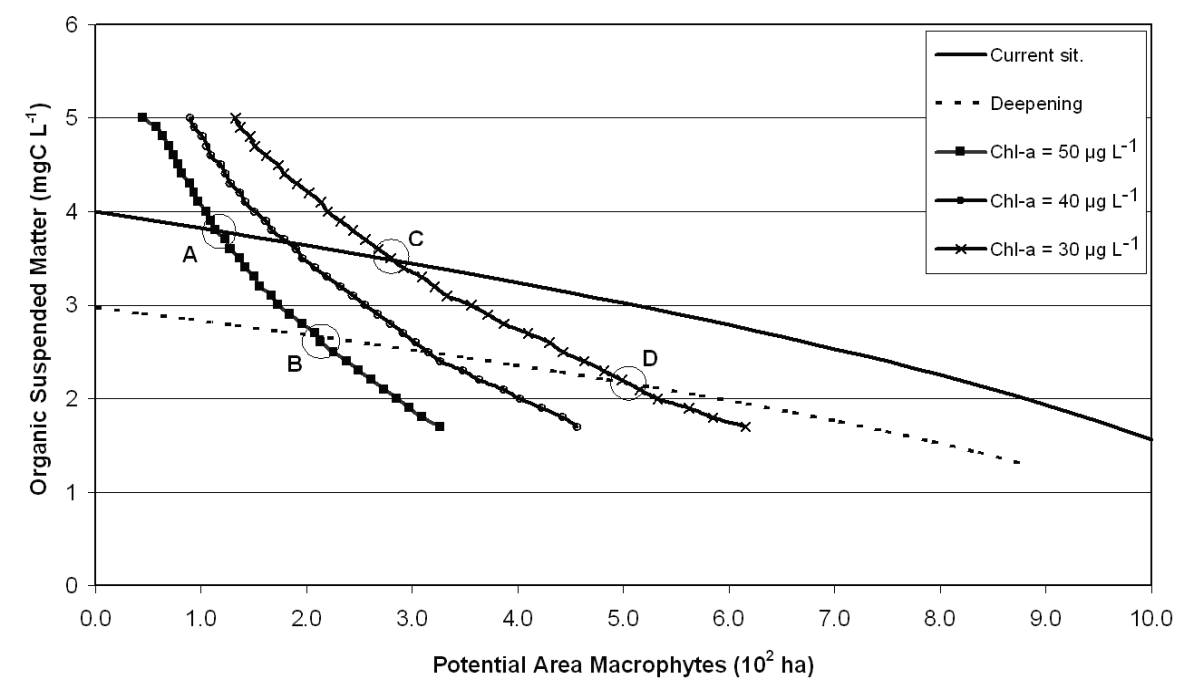

Fig. 7. Relation between potential area available for macrophytes where $4 \%$ light reaches the sediment (ha), the suspended matter and 3 predefined chlorophyll-a levels (black lines with markers) for the situation without the deepenings (black smooth line) and with deepenings (black dotted line). A: current situation; B: situation with deepening; C: current situation with P-load reduction; D: situation with deepening and P-load reduction.

Tab. 3. Quantification of the equilibrium points in figure 5.

\begin{tabular}{lcccc}
\hline & Unit & Current situation Only P reduction Only deepening & Deepening and P reduc. \\
\hline Potential area for macrophytes & $(\mathrm{ha})$ & 111 & 282 & 210 \\
Equilibrium concentr. of organic suspended matter & $\left(\mathrm{mg} \mathrm{C} \mathrm{L} \mathrm{L}^{-1}\right)$ & 3.8 & 3.5 & 2.7 \\
Attenuation coefficient & $\left(\mathrm{m}^{-1}\right)$ & 2.5 & 2.0 & 2.2 \\
Max. depth of occurrence of macrophytes & $(\mathrm{m})$ & 1.3 & 1.6 & 1.5 \\
\hline
\end{tabular}

and thus the potential area for macrophyte growth (as described in methods section) are shown in figure 7. In points A to D equilibria are met where the potential area covered with macrophytes is in line with the calculated suspended matter and chlorophyll- $a$ levels. Table 3 gives an overview of the exact numbers belonging to these points. The deepening creates 100 ha additional area potentially suitable for macrophyte development. Reduction of P-load leading to a decrease in average chlorophyll- $a$ levels from $50 \mu \mathrm{g} \mathrm{L}^{-1}$ to $30 \mu \mathrm{g} \mathrm{L}^{-1}$ will increase this area in current situation with 171 ha. In combination the two measures enhance each other and lead to an increase of 391 ha potentially suitable for macrophytes.

\section{DISCUSSION}

Organic suspended sediment problems in large shallow peat lakes have not been receiving much attention in the last decades. However, the problems derived from detritus in such lakes and in similar lakes throughout Europe have not diminished. With the current revival of interest in clear waters, caused by the Water Framework Directive requirements (European Union 2000) the topic has gained renewed attention. The measure here proposed, to reduce the suspended matter concentrations by means of a local deepening, is also considered for other large shallow lakes in the Nether- lands, such as Lake Markermeer and various other large (wind affected) peat lakes. The locations and depth used for the deepenings in our case study are only illustrative and changes in these parameters will affect the resulting suspended matter concentrations and resulting transparency in the lake. In this study we have not assessed the potential effects of thermal stratification in the deepening which can occur in summer periods although this is likely to have some effects on the nutrient balance in the lake. As shown through the suspended matter balance not only increasing the volume of the lake, but also reducing erosion helps to decrease the concentrations of suspended matter. Other types of measures focusing on such erosion reducing measures (e.g., physical structures such as wave barriers and capping sediment with more stable sand) have been proposed as equally feasible alternatives (James \& Barko 1994; Gulati et al. 2008).

Large fetches mechanically disturb macrophyte and especially helophytes development due to wind driven wave action (Coops \& Vanderveld 1996; Schutten et al. 2004). Based on standard theory on wind driven wave movements and resulting orbital motion following Hurdle \& Stive (1989) a fetch threshold can be calculated below which orbital motions do not reach the bed. For Lake Loosdrecht this fetch should be less than $500 \mathrm{~m}$, given the lakes depth of $1.8 \mathrm{~m}$, to reduce the wave and flow patterns to the extent that bottom shear stress and 
thus erosion is virtually limited. When resuspension is stopped the transparency will increase due to settlement of flocked particles. This was confirmed for Lake Loosdrecht by light attenuation and suspended matter measurements after a recent period of ice cover on the lake from $24^{\text {th }}$ December 2008 to $20^{\text {th }}$ of January 2009 (unpubl. data waterboard) which show that during this prolonged period the attenuation coefficient dropped to $1.6 \mathrm{~m}^{-1}$ which is comparable to our calculated situation without erosion. A week after ice cover disappeared attenuation coefficients were back to the average $2.6 \mathrm{~m}^{-1}$ due to wind driven resuspension.

The results of plotting the measured organic suspended matter and wind speeds (Fig. 3) do show a positive relation, but with a large variation around the average trend line. The high suspended matter recordings at low wind speeds are almost all summer samples where additional resuspension by biological and anthropogenic activities is expected. The few recordings of low suspended matter concentrations at higher wind speeds are dominated by early may samples, which are normally associated with the clear water spring phase in presence of sufficient volumes of zooplankton. Also, wind direction is not taken into account in this relationship, but is likely of influence on the recorded suspended matter data, as fetch and thereby wave driven resuspension is directly depending on wind direction. The effects of a potentially developing biofilm in periods of low wind have not been observed on undisturbed samples we took to the lab and left resting over a period of 2 weeks at room temperature.

In our case study of Lake Loosdrecht, in the current situation 111 ha of the lake is predicted to have a suitable light climate. However, field observations show that only a few patches of white and yellow water lilies exist in very shallow and well protected areas, but submerged macrophytes are almost nowhere recorded. It is expected that the fluffy epipelic layer is too often too liquid for macrophyte establishment and that the current fish population of $110 \mathrm{~kg} \mathrm{ha}^{-1}$ (of which $50 \%$ bream, unpubl. data Water board) is contributing to the limited presence of macrophytes. We therefore use the word 'potential area' for macrophyte recolonization, as we did not include other potentially limiting habitat factors in the analyses. We assume that light is the first requirement before any colonization from seed will be possible. It is not known what the current propagule bank of the lake is. Van den Berg (2001) showed that for the successful germination of Characeae a seed bank of more than 10.000 propagules $\mathrm{m}^{-2}$ is necessary and that in high density areas of characean growth the propagule bank can be up to 1.7 million seeds. As Lake Loosdrecht is not isolated from its surroundings it is expected that a sufficient seed supply is available. Mesocosm experiments in adjacent Lake Breukeleveen showed that various submerged macrophyte species were able to recolonize after improvement of the light conditions
(Van Donk et al. 1994). Also, the active biological control measure carried out in nearby Terra Nova (Van de Haterd \& Ter Heerdt 2007) showed that macrophytes can quickly recolonize, although both examples were carried out in situations with smaller fetch $(<500 \mathrm{~m})$.

The reductions in chlorophyll- $a$ represent the measures envisaged to reduce P-loading to the lake. We have not included the potential shift in phytoplankton community and density due to improvement of the light climate. The effect of the deepening by itself on the available area for macrophyte recolonization has thus not taking into account that chlorophyll- $a$ levels might increase when more light becomes available.

The shift to clear state in the reoligotrophication process is not necessarily influenced by resuspension of organic detritus. In an analysis of 7 years of data from 15 shallow Danish lakes, Jeppesen et al. (2003) found that the reduction in phytoplankton biomass after external loading reductions or changes in abundance of plankti- and benthivorous fish was accompanied by a proportional reduction in detritus and inorganic suspended solids. Resuspension of non-algal organic or inorganic matter (average 54\% and 26\% resp.) accumulated in the sediment did not delay the recovery of these lakes. Still, the debate on the issue remains as others such as Bachmann et al. (1999) found contradicting results for the $124 \mathrm{~km}^{2}$ large, shallow Lake Apopka.

Flocculation characteristics of organic suspended matter are an important driver for the dynamics in the suspended matter equilibrium. The sedimentation and erosion processes dominate the overall suspended matter balance, as they are a ten-fold higher than the production and loss terms. A better understanding of the suspended material characteristics is important in the analysis of the dynamics of the benthic-pelagic coupling (Droppo 2001). Unfortunately, most studies on (bio-) mechanical flocculation are carried out for inorganic cohesive sediments, especially in marine and estuarine systems (e.g., Berlamont et al. 1993; Winterwerp et al. 2006; Le Hir et al. 2007) or for suspended matter in fluvial systems (Wotton 2007). Adding chemical substances such as Fe and $\mathrm{Al}$ may enhance the natural flocculation of material, although Van Donk et al. (1994) showed that adding $\mathrm{FeCl}_{3}$ as a flocculant in a mesocosm experiment did not result in significant changes over a longer period of time. Also other chemical flocculants (e.g., using Alum) can enhance flocculation (Wang et al. 2009) and are applied most frequently with the intention to bind with in-lake phosphorous (Lewandowski et al. 2003). However, applying this types of treatments on large, shallow, wind driven lakes where bottom shear stresses are strong enough for near constant resuspension seems no sustainable solution. We foresee that, although P-load reduction will remain the prime issue within water management of large shallow lakes, more attention to the other components affecting the under- 
water light climate will be necessary to comply with WFD requirements.

\section{CONCLUSIONS}

Local deepenings in large wind-influenced shallow lakes with a high concentration of organic suspended matter will facilitate the reduction of this material through an increase in lake volume. Flocculation is the main process by which the small particles are able to sink to the bed. However, even small disturbances of the lake bed (comparable with $3 \mathrm{~cm} \mathrm{~s}^{-1}$ flow) already break up the flocs and cause resuspension of the material. In the current situation for Lake Loosdrecht the production of new organic suspended matter through primary production and peat decay is a magnitude 10 lower than the constant sedimentation and resuspension of already present material in the water on annual basis. The contribution of living algae to the total attenuation coefficient is an additional factor to take into account when assessing the effect of the deepenings on potential area for macrophyte recolonization. Therefore it appears that creation of local deepenings in eutrophic shallow peat lakes in combination with further reduction of P-load may give an overall higher result than these measures individually.

\section{ACKNOWLEDGEMENTS}

This study was initiated and funded by the Water board 'Amstel Gooi and Vecht'. Part of this study was funded by Delft Cluster contract CT0503. Authors acknowledge John Cornelisse, Walther van Kesteren, Han Winterwerp, Winnie Rip, Jacques van Alphen and Hans Los for their valuable discussions and contributions to this work and two anonymous referees for further improvement of the manuscript.

\section{REFERENCES}

Andersen, T.J. 2001. Seasonal variation in erodibility of two temperate, microtidal mudflats. Estuarine, Coastal, and Shelf Science, 53: 1-12.

Bachmann, R.W., M.V. Hoyer \& D.E. Canfield Jr. 1999. The restoration of Lake Apopka in relation to alternative stable states. Hydrobiologia, 394: 219-232.

Banse, K. 1977. Determining the Carbon to Chlorophyll ratio of natural phytoplankton, Mar. Biol., 41:199-212.

Berlamont, J., M. Ockenden, E. Toornman \& J. Winterwerp. 1993. The characterisation of cohesive sediment properties. Coastal Engineering, 21:105-128.

Best, E.P.H., D. De Vries \& A. Reins. 1984. The macrophytes in the Loosdrecht lakes: A story of their decline in the course of eutrophication. Verh. Internat. Verein. Limnol., 22: 868-875.

Booij, N., R.C. Ris \& L.H. Holthuijsen. 1999. A third-generation wave model for coastal regions, 1. Model description and validation. J. Geophys. Res., 104 (C4): 7649-7666.

Buiteveld, H. 1995. A model for calculation of diffuse light attenuation (PAR) and Secchi depth. Netherlands J. of Aq. Eco., 29(1): 55-65.

Chambers, P.A. 1987. Nearshore occurrence of submersed aquatic macrophytes in relation to wave action. Can. J. Fish. Aquat. Sci., 44: 1666-1669.
Coops, H. \& G. Vandervelde. 1996. Effects of waves on helophyte stands: Mechanical characteristics of stems of Phragmites australis and Scirpus lacustris. Aquatic Botany, 53(3-4): 175-185.

De Winton, M.D., M.T. Casanova \& J.S. Clayton. 2004. Charophyte germination and establishment under low irradiance. Aquatic Botany, 79: 175-187.

Droppo, I.G. 2001. Rethinking what constitutes suspended sediment. Hydrological Processes, 15(9): 1551-1564.

European Union. 2000. Directive 2000/60/EC of the European Parliament and of the Council of 23 October 2000 establishing a framework for Communities in the field of water policy, Official Journal of the European Communities, L 327/1, 22.12.2000

Gons, H.J., R. Veeningen \& R. Van Keulen. 1986a. Effects of wind on a shallow lake ecosystem: resuspension of particles in the Loosdrecht lakes. Hydrobiological Bulletin, 20(1/2): 109-120.

Gons, H.J., R.D. Gulati \& L. Van Liere. 1986b. The eutrophic Loosdrecht lakes: current ecological research and restoration perspectives. Hydrobiological Bulletin, 201(1/2): 67-75.

Gulati, R.D. \& E. Van Donk. 2002. Lakes in the Netherlands, their origin, eutrophication and restoration: state-of-the-art review. Hydrobiologia, 478: 73-106.

Gulati, R.D., L.M. Dionisio Pires \& E. Van Donk. 2008. Lake restoration studies: Failures, bottlenecks and prospects of new ecotechnological measures. Limnologica, 38: 233247.

Harris, G.P. 1978. Photosynthesis, Productivity and Growth: The Physiological Ecology of Phytoplankton. Arch. Hydrobiol. Ergebn. Limnol., 10 (I-IV): 1-171.

Hurdle, D.P. \& R.J.H. Stive. 1989. Revision of SPM 1984 wave hindcast model to avoid inconsistencies in engineering applications. Coastal Engineering, 12: 339-351.

Istvanovics, V., M. Honti, A. Kovacs \& A. Osztoics. 2008. Distribution of submerged macrophytes along environmental gradients in large, shallow Lake Balaton (Hungary). Aquatic Botany, 88(4): 317-330.

James, W.F. \& J.W. Barko. 1994. Macrophyte influences on sediment resuspension and export in a shallow impoundment. Lake and Reserv. Manage., 10(2): 95-102

Jeppesen, E., J.P. Jensen, M. Søndergaard, K.S. Hansen, P.H. Møller, H.U. Rasmusen, V. Norby \& S.E. Larsen. 2003. Does resuspension prevent a shift to a clear state in shallow lakes during reoligotrophication? Limnol. Oceanogr., 48(5): 1913-1919.

Kalin, M. \& M.P. Smith. 2007. Germination of Chara vulgaris and Nitella flexilis oospores: What are the relevant factors triggering germination? Aquatic Botany, 87 (2007) 235-241.

Kowalski, W.P. 2004. Investigation of fine grains distribution using sedimentation analysis. J. of Materials Processing Technology, 157-158: 561-565.

Küster, A., R. Schaible \& H. Schubert. 2004. Light acclimation of photosynthesis in three charophyte species. Aquatic Botany, 79: 111-124.

Le Hir, P., Y. Monbet \& F. Orvain. 2007 Sediment erodability in sediment transport modelling: Can we account for biota effects? Continental Shelf Research, 27(8): 1116-1142

Lesser, G.R., J.A. Roelvink, J.A.T.M. Van Kester \& G.S. Stelling. 2004. Development and validation of a three-dimensional morphological model. Coastal Engineering, 51: 883-915.

Lewandowski, J., I. Schauser \& M. Hupfer. 2003. Long term effects of phosphorus precipitations with alum in hypereutrophic Lake Susser See (Germany). Water Research, 37(13): 3194-3204

Lyche Solheim, A., S. Rekolainen, S.J. Moe, L. Carvalho, G. Phillips, R. Ptacnik, W.E. Penning, L.G. Toth, C. O'Toole, A.L. Schartau \& T. Hesthagen. 2008. Ecological threshold responses in European lakes and their applicability for the 
Water Framework Directive (WFD) implementation: synthesis of lakes results from the REBECCA project. Aquatic Ecology, 42: 317-334.

Meijer, M.L., I. De Boois, M. Scheffer, R. Portielje \& H. Hosper. 1999. Biomanipulation in shallow lakes in The Netherlands: an evaluation of 18 case studies. Hydrobiologia, 408: 13-30.

Saffman, P.G. \& J.S. Turner. 1956. On the collision of drops in turbulent clouds. J. Fluid Mech., 1: 16-30.

Schutten, J., J. Dainty \& A.J. Davy. 2004. Wave-induced hydraulic forces on submerged aquatic plants in shallow lakes. Annals of Botany, 93:333-341

Søndergaard, M., E. Jeppesen, T.L. Laurdsen, C. Skov, E.H. Van Nes, R. Roijackers, E. Lammens \& R. Portielje. 2007 Lake restoration: successes, failures and long-term effects. Journal of Applied Ecology, 44: 1095-1105.

Strickland, J.D.H. 1960. Measuring the Production of Marine Phytoplankton. Fish. Res. Bd Can. Bull., No. 122, Ottawa.

Van de Haterd, R.J.W. \& G.N.J. Ter Heerdt. 2007. Potential for the development of submerged macrophytes in eutrophicated shallow peaty lakes after restoration measures. Hydrobiologia, 584: 277-290.

Van den Berg, M.S. 2001. Propagule bank buildup of Chara aspera and its significance for colonization of a shallow lake. Hydrobiologia, 462 (1-3): 9-17
Van Donk, E., M.P. Grimm, P.G.M. Heuts, G. Blom, K. Everards \& O.F.R. Van Tongeren. 1994. Use of mesocsms in a shallow eutrophic lake to study the effects of different restoration measures. Arch. Hydrobiol. Beih., 40: 283-294.

Van Leussen, W. 1994. Estuarine macroflocs and their role in fine-grained sediment transport. $\mathrm{PhD}$ Dissertation University of Utrecht, ISBN 90-393-0410-6.

Van Liere, L. 1986. Loosdrecht lakes, origin, eutrophication, restoration and research programme. Hydrobiological Bulletin, 20: 9-15.

Van Liere, L. \& R.D. Gulati (Eds). 1992. Restoration and recovery of shallow eutrophic lake ecosystems in the Netherlands. Hydrobiologia, 233 - special issue.

Wang, Y., B.Y. Gao, X.M. Xu, W.Y. Xu \& G.Y. Xu. 2009. Characterization of floc size, strength and structure in various aluminum coagulants treatment. Journal of Colloid and Interface Science, 332(2): 354-359.

Wotton, R.S. 2007. Do benthic biologists pay enough attention to aggregates formed in the water column of streams and rivers? J. North Am. Benth. Soc. 26(1): 1-11.

Winterwerp, J.C., A.J. Manning, C. Martens, T. De Mulder \& J. Vanlede. 2006. A heuristic formula for turbulence induced flocculation of cohesive sediment. Est. Coast. and Shelf Sci., 68: 195-207.

\section{APPENDIX A: Detailed description of the suspended matter balance}

Van Leussen (1994) showed that the flocculation time $T_{f l o c}^{-1}$ can be expressed in terms of a flocculation efficiency $\alpha$, the zeta potential $\phi$ and a collision term G.

$$
T_{\text {floc }}^{-1} \propto \alpha \phi G \quad\left[s^{-1}\right] ; \quad \phi=\frac{c_{\text {suspended }}}{\rho_{\mathrm{det}}}
$$

In stagnant waters $\mathrm{G}$ is predominantly determined by the differences in fall velocity of various particles $\Delta w_{s}\left(G_{d i f}\right.$ differential settlement) and the diameter $\mathrm{d}$ of the particles, in turbulent waters chaotic pathways result in the same $G$. Saffman \& Turner (1956) showed that:

$$
G_{d i f}=\frac{\pi \Delta w_{s}}{d} \quad ; \quad G_{t u r}=\sqrt{\frac{8 \pi}{15} \frac{\varepsilon}{v}}
$$

In which $\varepsilon$ is the energy dissipation of turbulence (Watt $\mathrm{kg}^{-1}$ or $\mathrm{m}^{2} \mathrm{~s}^{-3}$ ) and $v$ the kinematic viscosity $\left(\mathrm{m}^{2} \mathrm{~s}^{-1}\right)$.

The flocculation parameter $\tau_{f l o c}$ is used in the calculation of the total gross sedimentation flux for the current situation (indicated with an additional ${ }_{o}$ ):

$$
V_{L L} \dot{M}_{f l o c}=\frac{V_{L L}}{\tau_{f l o c, 0}} c_{0}^{2} \quad\left[k g s^{-1}\right]
$$

in which:

$$
\tau_{\text {floc }}=c_{\text {suspended }} T_{\text {floc }}
$$

which implies that flocculation time $T_{f l o c}$ is depending on the available concentration of suspended particles and:

$$
\left(V_{L L}+V_{d}\right) \dot{M}_{f l o c}=\frac{V_{L L}+V_{d}}{\tau_{f l o c, 1}} c_{1}^{2} \quad\left[k g s^{-1}\right]
$$

for the situation with deepenings (indicated with an additional ${ }_{1}$ ).

The temporal and spatially specific erosion flux $E\left(\mathrm{~kg} \mathrm{C} \mathrm{m}^{-2} \mathrm{~s}^{-1}\right)$ is integrated over the bed surface $A_{L L}$ as:

$$
\eta_{0}{\overline{E A_{L P}}}^{0}
$$

in which the superscript ' 0 ' indicated the current situation and $\eta$ the fraction of the bed surface not susceptible to erosion (e.g., due to macrophyte presence).

Or:

$$
{\overline{E A_{L L}}}^{1} \equiv \eta_{1}{\overline{E\left(A_{L L}-A_{d}\right)}}^{1}+{\overline{E A_{d}}}^{1}
$$


For situations with the deepenings (indicated with superscript ' 1 ') in which we assume erosion from the bed in the deepenings is negligible when deeper than $4 \mathrm{~m}$.

To counterbalance the increased erosion outside the deepenings (see results of $3 \mathrm{D}$ calculation, figure 3 ) we include $\chi_{0.1}$ in A-7 and calibrate terms within \{\} against the current situation:

$$
{\overline{E A_{L L}}}^{1}=\eta_{1}{\overline{E\left(A_{L L}-A_{d}\right)}}^{1}=\frac{\eta_{1}}{\eta_{0}} \chi_{1,0}\left\{\eta_{0}{\overline{E A_{L L}}}^{0}\right\}\left(1-\frac{A_{d}}{A_{L L}}\right)
$$

A-8 shows that a reduction of the erodable area due to deepenings can be counterbalanced by the additional erosion directly outside the deepenings. For small deepenings relative to the total lake surface area the total shear stress on the bed resulting from the hydrostatic pressure due to wind set up we can estimate $\chi_{1,0}$ :

$$
\chi_{1,0} \approx 1+\frac{A_{d}}{A_{L L}} \quad ; \quad \frac{A_{d}}{A_{L L}} \square 1
$$

Combining A-8 and A-9 gives:

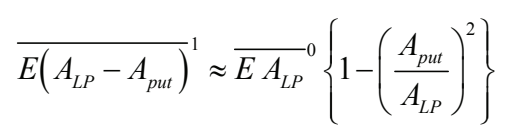

which shows that the reduction of the current erodable lake surface with the proposed deepenings of 120 ha (12\% reduction the erodable surface area) results in only $1.5 \%$ reduction of erosion.

Next to these terms we assume that the production of suspended matter due to algae $\left(P_{a}\right)$ and decay of peat $\left(P_{p}\right)$ is equal with and without the deepenings. Also, the amount of inlet water $\left(Q_{c}\right)$ and the mineralization time of the organic suspended matter $\left(T_{m}\right)$ remain the same in both situations.

The total balance for the current situation (indicated with ' 0 ') is than:

$$
V_{L L} \frac{d c_{0}}{d t}=\left(P_{\mathrm{a}}+P_{\mathrm{p}}\right)_{0}-Q c_{0}-\frac{V_{L L}}{T_{M}} c_{0}-\frac{V_{L L}}{\tau_{f l o c, 0}} c_{0}^{2}+\eta_{0}{\overline{E A_{L L}}}^{0}
$$

and for the situation with deepenings (indicated with '1'):

$$
\left(V_{L L}+V_{d}\right) \frac{d c_{1}}{d t}=\left(P_{\mathrm{a}}+P_{\mathrm{p}}\right)_{1}-Q c_{1}-\frac{V_{L L}+V_{d}}{T_{M}} c_{1}-\frac{V_{L L}+V_{d}}{\tau_{f l o c, 1}} c_{1}^{2}+\eta_{1}{\overline{E\left(A_{L L}-A_{d}\right.}}^{1}+{\overline{E A_{d}}}^{1}
$$

Assuming that in the current situation the lake is in an equilibrium (the suspended matter mass is constant over the year) gives:

$$
\eta_{0}{\overline{E A_{L L}}}^{0}=Q c_{0}+\frac{V_{L L}}{T_{M}} c_{0}+\frac{V_{L L}}{\tau_{f l o c, 0}} c_{0}^{2}-\left(P_{\mathrm{a}}+P_{\mathrm{p}}\right)_{0}
$$

and for the new equilibrium with the deepings than follows:

$$
\begin{aligned}
& \left(\frac{V_{L L}+V_{d}}{\tau_{f l o c, 1}}\right) c_{1}^{2}+\left(Q+\frac{V_{L L}+V_{d}}{T_{M}}\right) c_{1}= \\
& \chi_{1,0}\left(1-\frac{A_{d}}{A_{L L}}\right)\left\{\frac{V_{L L}}{\tau_{f l o c, 0}} c_{0}^{2}+\left(Q+\frac{V_{L L}}{T_{M}}\right) c_{0}\right\}+\left\{\left(P_{\mathrm{a}}+P_{\mathrm{p}}\right)_{1}-\chi_{1,0} \frac{\eta_{1}}{\eta_{0}}\left(1-\frac{A_{d}}{A_{L L}}\right)\left(P_{\mathrm{a}}+P_{\mathrm{p}}\right)_{0}\right\}
\end{aligned}
$$

The flocculation time was defined using the results of the centrifuge experiments for the Loosdrecht samples from which followed that the flocculation efficiency $\alpha$ is approx. 0.1, which is in accordance with Van Leussen (1994) and a $\phi$ of $-5 \mathrm{mV}$. $G_{d i f}$ was determined to be $1 \mathrm{~s}^{-1}$ using the fall velocity variation of $0.1 \mathrm{~m}_{\text {day }}{ }^{-1}$ between particles and an average particle diameter of $3 \mu \mathrm{m}$. $G_{t u r} \leq 1 \mathrm{~s}^{-1}$ for Loosdrecht in most of the water column. This allows linking the experimental data to the hydrodynamical 3D calculations, which show that turbulence is too low for breaking of the flocs in the water column. Only directly above the shallow bottoms wave action caused fracture of the flocs back to their original state. Thus the gross sediment flux can be assumed equal to the mass flux for flocculation. A-5 shows that the sedimentation flux (in ton $\mathrm{C}^{-1}$ ) decreased squared with a decrease in concentration and the sedimentation flux increases due to the additional available volume that the deepenings provide. 